\title{
Self-Study Interactive Lectures
}

\section{H. David Brecht, Suzanne M. Ogilby, and Eugene Sauls California State University, Sacramento, USA}

\section{brecht@csus.edu ogilbysm@csus.edu saulseh@csus.edu}

\begin{abstract}
This paper presents the groundwork development of a computer assisted learning program called SelfStudy Interactive Lectures (SSIL). SSIL is an enriched classroom presentation that uses transcriptquality lecture notes and OFFICE programming features to facilitate and empower students' learning at a greater depth than otherwise obtainable. A major feature of SSIL is its response to variation in students' abilities to understand complex material, such as accounting. The paper provides an overview of SSIL and discusses the implications for the scope and depth of lecture coverage. As a case study, students in classes using SSIL were surveyed and the results of the surveys are reported in the paper. This is seed research in nature, opening up opportunities for future research into the SSIL methodology's connection to pedagogical theory and its testing for more general application in other classroom settings.
\end{abstract}

Keywords: Computerized education, inno vation, students

\section{Introduction}

A previous paper (Brecht, 2000) introduced the exploitation of easily used web-authoring technology to provide students with interactive tutorials. These tutorials were developed to address specific topics in accounting, for example activity based costing in managerial accounting. The technology is Microsoft OFFICE, where Internet Explorer displays cross-linked files in HTML, EXCEL (xls files), WORD (doc files), and POWERPOINT (ppt files). This paper uses many of the interactive tools of the previous paper, but significantly changes the application from a specific topic to the entire set of lectures for a course. The same software is used with Microsoft OFFICE 2002 instead of an earlier version of OFFICE. Overall, this paper pre sents, for entire courses, the groundwork development of a computer assisted learning program called Self-Study Interactive Lectures (SSIL).

The goal of interactive tutorials or lectures is to give students an appropriately thorough presentation of topic concepts, quantitative methods, and problem solving examples. A student interacts with an interactive file in two basic ways. (1) A student can select additional instruction through the originating software or alternative media. For example, while reading a WORD discussion in the browser, s/he can choose to link to a POWERPOINT presentation of underlying principles. (2) In an EXCEL file viewed in the browser, a student solves problems by inputting data to defined fields. Context sensitive help is available through the use of comments, cond itional formatting, formula auditing tracing arrows, hidden format/command, and if- function pop-up messages. A student can also choose to link to files with supplementary instructions, discussion, or alternative

Material published as part of these proceedings, either on-line or in print, is copyrighted by Informing Science. Permission to make digital or paper copy of part or all of these works for personal or classroom us e is granted without fee provided that the copies are not made or distributed for profit or commercial advantage AND that copies 1) bear this notice in full and 2) give the full citation on the first page. It is permissible to abstract these works so long as credit is given. To copy in all other cases or to republish or to post on a server or to redistribute to lists requires specific permission from the publisher at Publisher@Informingscience.org solution approaches.

The characteristics of self-study interactive lectures (SSIL) are presented first - in the first two major sections of the paper. The focus of the discussion is on what features of SSIL transform a lecture supported by outline-quality lecture notes into a self-study interactive lecture. A SSIL is an enriched classroom presentation that uses tran- 


\section{Self-Study Interactive Lectures}

script quality lecture notes and OFFICE programming features to facilitate and empower student learning at a greater depth than otherwise attainable. The use of lecture files in class lectures and by students for self-study is discussed. In addition, an overview of how OFFICE software is used and files programmed for interactive lectures is provided.

The third major section of the paper discusses the power of self-study interactive lectures, including how moving from topic-specific tutorials to SSIL has significant implications for the scope and depth of lecture coverage and empowering student self-study. The media used - files in Microsoft OFFICE programs - does not change between the topic-specific tutorial applications and SSIL; however, the power of the tools is greatly increased.

The fourth major section is a case study of students' responses to survey instruments. These students were in courses where SSIL was class tested - two junior/senior-level sections of a cost accounting course. This feedback is informal but provides an initial indication of student acceptance of the method and whether students' learning benefits from the pedagogy. Future student and/or instructor feedback will focus on the contributions of SSIL for structuring in-class lectures, enabling student self-study, and enhancing learning.

This paper is seed research in nature, opening up opportunities for future research into the SSIL methodology's connection to pedagogical theory and its testing for more general application in other classroom settings.

\section{Characteristics of Self-Study Interactive Lectures}

A self-study interactive lecture is a set of concepts and Microsoft OFFICE programming tools applied in a particular lecture-topic context. Using SSIL files, a student can study at home all of the facets of a lecture in a manner that faithfully reproduces the content and sequence of the in-class lecture. Four essential characteristics of SSIL are embedded in the lecture files at various points.

1. A set of lecture notes that represents a substantially complete transcription of the lecture content. This set of lecture notes is organized into a series of files with increasing depth and breadth of coverage as the lecture proceeds through the files. For a particular text chapter, the files begin with an anchor file. It introduces the main topic segments to be covered with links to the segment files. A segment file contains detailed lecture material and/or it introduces elements of the topic with links to the element files. Segment element files are further detailed lecture notes - concepts, illustrative problems, and assigned homework. Separately, a summary file exists that contains the totality of the anchor file and its subsets. Future development of these files will include an outline file that serves as a site map for all the other files in a chapter series.

2. "Off-line" topic detail that includes supplementary topic material to support students needing tutorial support and/or extended topic material to offer extended-development opportunities to more advanced students. This material is off-line in that it must be linked to from a segment or segment element file and is not intended as part of the lecture to be presented in class. It is a file that is available to and can be accessed by students on an as-needed basis.

3. "Help" at context-sensitive points in the lecture. This material exists as short, pop-up details that remind students of pertinent concepts, definitions, and formula explanations that relate to the discussion or problem being solved. The "helps" are accessed by mouse-rollovers to exhibit comment balloons. In EXCEL files, the entry of incorrect answers into a field can activate automatic pop-up "helps" using if-functions and conditional formats. Also, students can use formulaauditing to view arrows that trace relationships between the general content of cells. These tracing relationships can be created as phantom formulas beside cells intended for data entry.

4. Interactive dialogues for lecturing concepts or problems, in-class discussion, or testing. 
These characteristics are further described and/or presented in this section through the use of a specific lecture example. The example is a lecture on "making investment decisions using financialevaluation methods," a group of topics found in cost accounting and finance textbooks - usually under chapter titles of "relevant cost analysis" and "time value of money analysis." The design features of the SSIL are discussed in the context of this example since SSIL design and tools-used are application specific. That is, different topics require different SSIL designs, and different instructors covering the same basic topic will design their lectures and choice of programming tools differently.

Figure 1 is a graphic representation of the series of files used for the example lecture. To visua lize the lecture's sequence, envision a decision tree and its numbered nodes. The lecture starts with the anchor file (node 1) and moves completely through each topic segment and its elements in sequence (nodes 2, 3, 4, and node 5 including its elements a. through f.). Movement through the separately stored segments and elements of the lecture involves linking to separate files that open in separate windows for quick cross-navigation.

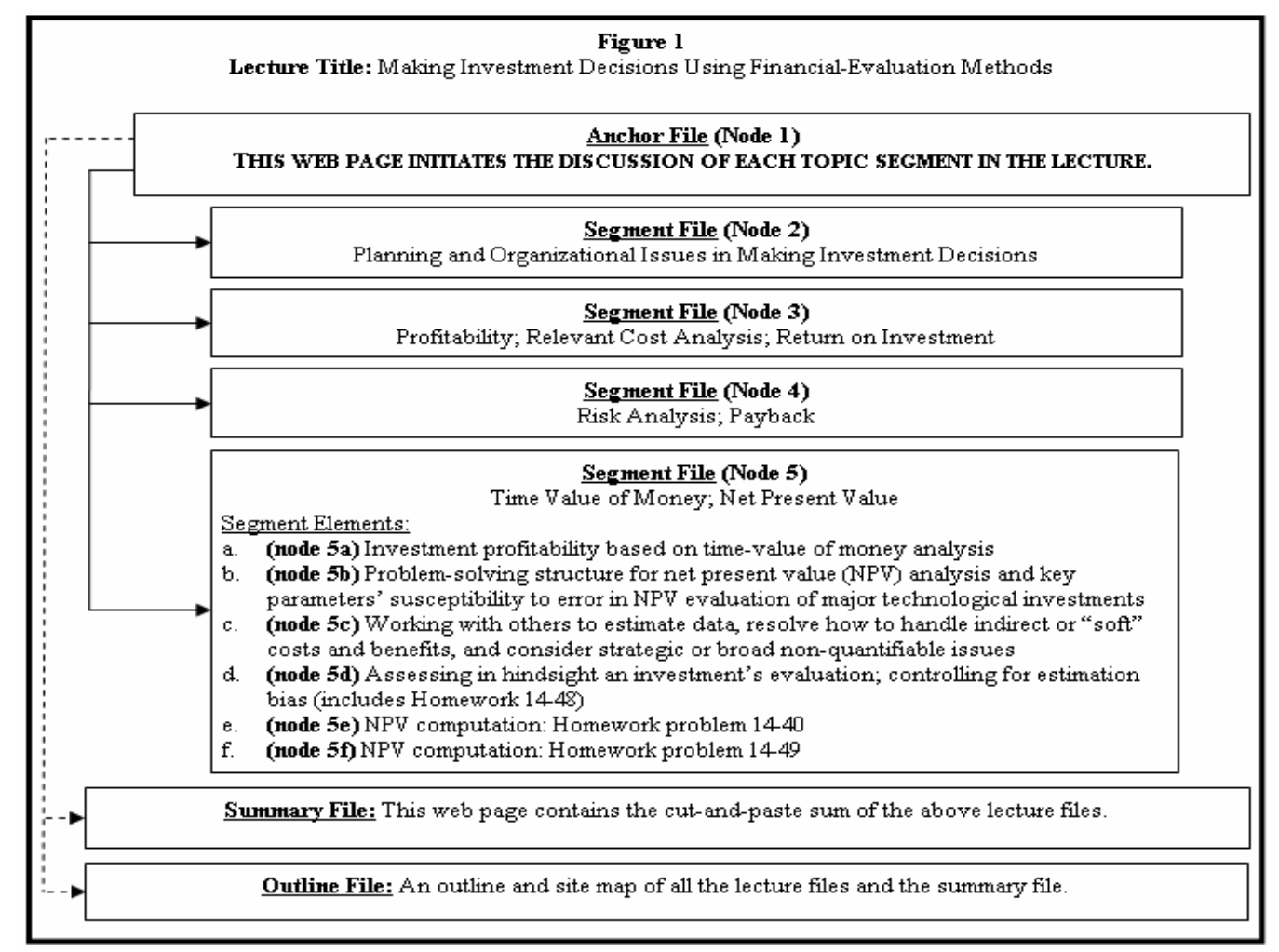

\section{Anchor File}

The anchor file is the web page that initiates the discussion of each topic segment in the lecture for a textbook chapter. It is not an outline or site map of all other lecture files, but is the first node used to briefly introduce and branch (link) to the topic segments of the lecture. This file provides a brief abstract of the lecture and anchors the different conceptual or computational directions the topic will take. One must always come back to the anchor file to initiate a new topic segment sequence. The anchor file is created as a WORD-generated html file.

The anchor file and, whenever possible, all of the other lecture files intend to have a lot of page space that is free of typing (so called "white space") to make the page appear uncluttered and inviting to read. In the same sense, it is considered desirable not to have too much information on the screen lectured at any point in time. The idea of the anchor file is to engage students with an overview of the lecture - its beginning, middle, and end. 


\section{Segment File (node 5)}

The sum of all files for a segment reflects the full array of ideas for the topic, but this is divided over several files (the anchor, topic segment, and segment element files). The assumption is that many stur dents have not read the material before class and may have difficulty holding in mind a complex pattern of thoughts on first hearing. The ability to see on one page all facets of the discussion at hand - and no more - is important. Coverage of the topic segment begins with the text in the anchor file - an introduction or very brief abstract of the topic segment. It is a beginning that introduces and motivates the segment's coverage.

A smooth transition from file to file gives discussion continuity, so that in moving from page to page students stay in context as they would with any verbal presentation. On any given page, the student sees the full relevant text of discussion and no more. Each page (file) represents a substantially complete transcript of the lecture content, not necessarily word-for-word, but thought-for-thought.

Figure 2 illustrates the use of SSIL on the time value of money and net present value topics. In the segment file (node 5), the introductory text from the anchor file is repeated and the content is developed further. For this topic, the segment file acts as an anchor file for each of the a. through $\mathrm{f}$. segment elements. The segment file is a WORD-generated html file.

\section{Segment Element Files (node 5b)}

Figure 2 illustrates the use of detailed self-study interactive lectures (node 5b). Putting this illustration in a specific topic context helps clarify the strategic placement of interactive techniques. This strategic placement is intended to enhance lecture comprehension, structure topic elements for more in-depth and motivated study, and structure quantitative problems for a more thorough understanding of the problemsolving approach and principles underlying the problem technique's application. Segment element 5.b. focuses on the coverage of concepts using WORD-generated doc files and EXCEL-generated xls files. Additionally, we paste sections of EXCEL (xls) worksheets into the doc file as Microsoft Excel Worksheet Objects. This paste-specia 1 procedure gives the instructor the ability to edit the sections during the lecture using WORD's <edit><worksheet object><edit> function. (Segment element files can also be created in PowerPoint, or WORD sections can be pasted into EXCEL files. Microsoft's browser, Internet Explorer, opens all of these files; although a file may have to be saved and reopened in the generating program to get full functionality.) These pasted worksheets are hidden using WORD's $<$ format $><$ font $><$ hidden $>$ feature, and revealed during the lecture using the $<$ hidden $>$ command (placed on the standard toolbar).

In the $5 \mathrm{~b}$ lecture, the central topic is "learning to structure and specify a net present value problem." The lecture is divided into five distinct parts (shown in Figure 2 for context). In Figure 3, we overlay Figure 2 with (1) the type of file and type of data entry (IN BOLD SMALL CAPS) and (2) the placement and nature of classroom activity and interactive techniques (in bold, lower case, italics) - condensing or deleting wording from Figure 2. Related discussion follows Figure 3.

\section{Figure 2: Node 5b Lecture Topic Details}

1. Present a problem-solving structure for net present value (discounting) analysis.

2. Set up a new-technology investment opportunity, and explain the information needed to use the NPV model in making the investment decision. As the needed information is explained, build a problem solving structure filled in with appropriate data and solution information.

a. Identify the benefits (revenues) and costs relevant to the investment decision. Discuss difficult estimation issues.

b. Estimate the revenues and costs' dollar values. Discuss difficult estimation issues. 
c. Decide the investment life over which benefits and costs continue. Discuss difficult estimation issues.

d. Explain the measurement of investment profitability as net present value, and define the required rate of return.

e. Review the NPV solution to the investment decision (the sum of parts 2.a. through 2.d.).

3. Examine the effects on the analysis of alternative dollar values (bigger dollars and more types of benefits) and longer investment life.

a. Update the 2.e. solution with revised data.

4. Examine the effects on the analysis of adjusting the rate of return for lower risk.

a. Update the 3.a. solution with revised data.

5. Summarize the example problem solutions in 2.e., 3.a., and 4.a. with a side-by-side comparison of the effects of alternative cash flows, investment life, and risk assumptions on long-term, technology investment decisions.

\section{Problem-Solving Structure - TEXT + PASTED EXCEL WORKSHEET OBJECT (USING WORD'S < HIDDEN> FORMAT/COMMAND); instructor lecture}

2. Opportunity-problem set-up and introduction to information explanation - TEXT; instructor lecture

a. Identify benefits \& costs; issues - TEXT; instructor lecture

Build problem-solving structure - PASTED EXCEL WORKSHEET OBJECT (USING < HIDDEN>); students contribute to build structure (using WORD's <worksheet object edit>)

b. Estimate dollar values; issues - TEXT; instructor lecture

Build problem-solving structure - PASTED EXCEL WORKSHEET OBJECT (USING < HIDDEN>);

students contribute to build structure (using WORD's <worksheet object edit>)

c. Investment life; issues - TEXT, instructor lecture

Build problem-solving structure - PASTED EXCEL WORKSHEET OBJECT (USING < HIDDEN>); students contribute to build structure (using WORD's <worksheet object edit>)

d. Explain NPV and ROR - TEXT; instructor lecture

Build problem-solving structure - PASTED EXCEL WORKSHEET OBJECT (USING < HIDDEN>); instructor lecture

e. Complete problem solution \& review the NPV components - TEXT + PASTED EXCEL WORKSHEET OBJECT (USING < HIDDEN>); students contribute to complete problem structure and solution (u sing WORD's <worksheet object edit>)

3. Examine alternative dollar \& life effects; 3.a. Update of 2.e. - LINK TO EXCEL XLS FILE with TEXT, instructor lecture + students contribute to solve problem

4. Examine lower risk \& ROR effects; 4.a. Update of 3.a. - LINK TO EXCEL XLS FILE with TEXT; in- 


\author{
structor lecture + students contribute to solve problem \\ 5. Compare 2.e., 3.a., 4.a. assumptions \& solutions - LINK TO EXCEL XLS FILE with TEXT; instructor \\ lecture
}

A review of Figure 3 reveals three patterns of how OFFICE programming of lecture notes are used in this particular application to transform what might have been elaborate lecture notes into a self-study interactive lecture.

1. The goal of controlling the amount of text that can be viewed at any given point in the lecture is achieved by using separate files for sections 1., 2., 3., 4., and 5., where all files open in separate windows so that quick cross-references between files are always possible. (Quick links between files from the same or different OFFICE program can be achieved using <alt-tab> or mouse clicks to open files listed on the taskbar.) Also, within sections 1. and 2., EXCEL Worksheet Objects are pasted, each approximately of screen width and an average of ten rows high (10 × 10 "tables"). To control when these objects can be seen, they are initially forma tted as "hidden." The instructor then uses the < hidden> command on the standard toolbar to toggle each one between being hidden and being able to be seen. No space is allocated to the object in hidden mode other than two characters used as place marks (e.g., “ $")$.

2. Students participate in a discussion to specify the problem-solving structure for a technology investment opportunity to engage them with the concepts in section 2 . This building process evolves from 2.a. through 2.d., and the problem is completed and solution components are reviewed in 2.e.. Each phase of the process has a worksheet object that is filled out in part from the previous discussions, and to which material must be added. Students can view the results of their participation entered in the structure on the screen; and, if the instructor wishes, the file can be FTPed to a server so that students can download it after class. Downloads are either as a WEB page save, or by FTPing from the server. In an electronic classroom, the file can be saved on the server, and the students instantly download it.

3. Separate EXCEL xls files are used in sections 3. and 5. in the same way that worksheet objects were used with each part of section 2. There are several advantages from going to xls files rather than using worksheet objects pasted in a WORD file. There is greater functionality from working directly in EXCEL. (To achieve the maximum functionality, the xls file must be saved and reopened in EXCEL. For example, present value functions could be introduced as part of the solution effort). A new file is needed to separate a section from a large amount of detail in other sections in order to control the amount of text that can be viewed at any given point in the lecture. In either a web course or electronic classroom context, the file can be downloaded by each student, solved as a homework or exam exercise, and uploaded by the student for grading. One of the authors uses a commercial internet service provider where files can be FTPed into the server. Alternatively, students can attach such a file to an email sent to the instructor.

A review of Figure 3 also suggests two ways in which student self-study benefits from a SSIL design.

1. Students can recreate the lecture sequence and content by beginning with the anchor file and progressing through the segment and segment element files. Thus, lectures can be "replayed" until the material is learned, placing emphasis on topics where the instructor placed it.

2. Students can interact with the key material by working with the worksheet objects (which they can open in EXCEL by a right-click <worksheet object><open> menu option within the doc file) and with the EXCEL xls files. This interaction involves "learning by doing" rather than only "by reading," and it is superior to traditional homework in that it can be strategically placed in the lecture at 
the point and in the context of the classroom discussion. Traditional homework comes from end-ofchapter textbook problems, and what is available may or may not cover points the instructor wishes to emphasize in lecture.

\section{Segment Element Files (node 5f)}

Figures 4 and 5 are detailed illustrations of a segment element that is a quantitative homework problem (Node 5f.). The placement and use of interactive techniques in the homework problem is designed to help students learn how to solve the problem and use the topic-analytic method. The main files are EXCEL xls files, and the help files are PowerPoint and html.

Figure 4 shows the $5 f$ homework problem's structure and solution. Figure 5 shows Figure 4 with the solution numbers removed and comments hidden. Related discussion follows Figure 4 and, subsequently, Figure 5.

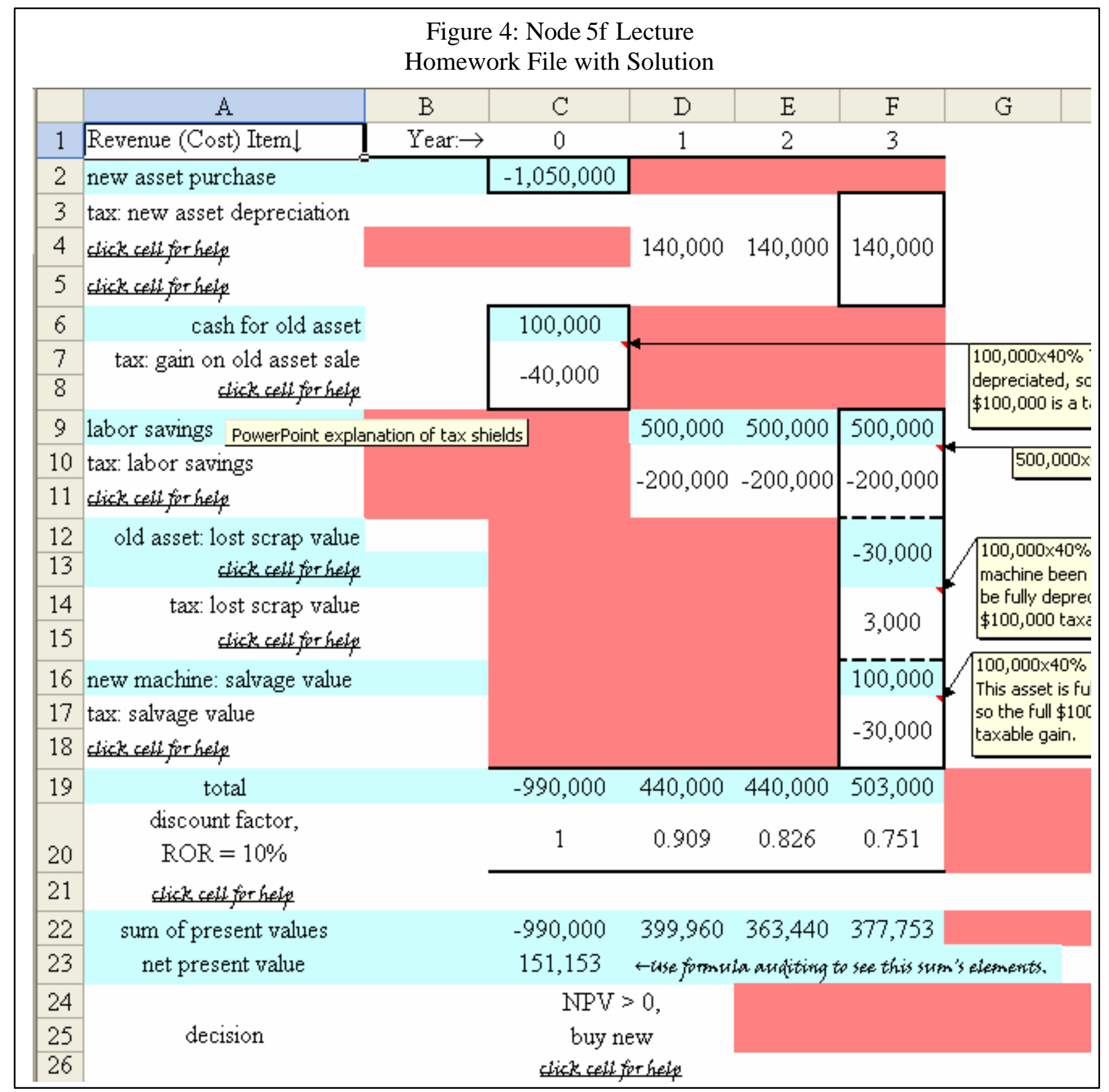




\section{Self-Study Interactive Lectures}

Figure 4 shows how students access the various "helps" available, and gives the solution to the problem. This solutio $\mathrm{n}$ file is available to students, so that the better students can go directly to it for review of their solution attempt - without having to enter their solution into the file shown in Figure 5. Students can use the Figure 4 file selectively, accessing "helps" to clarify issues with which they may be having difficulty. Students with difficulties associated with English as a second language, weaker analytic ability or weaker prerequisite background have the Figure 5 file to work with extensively.

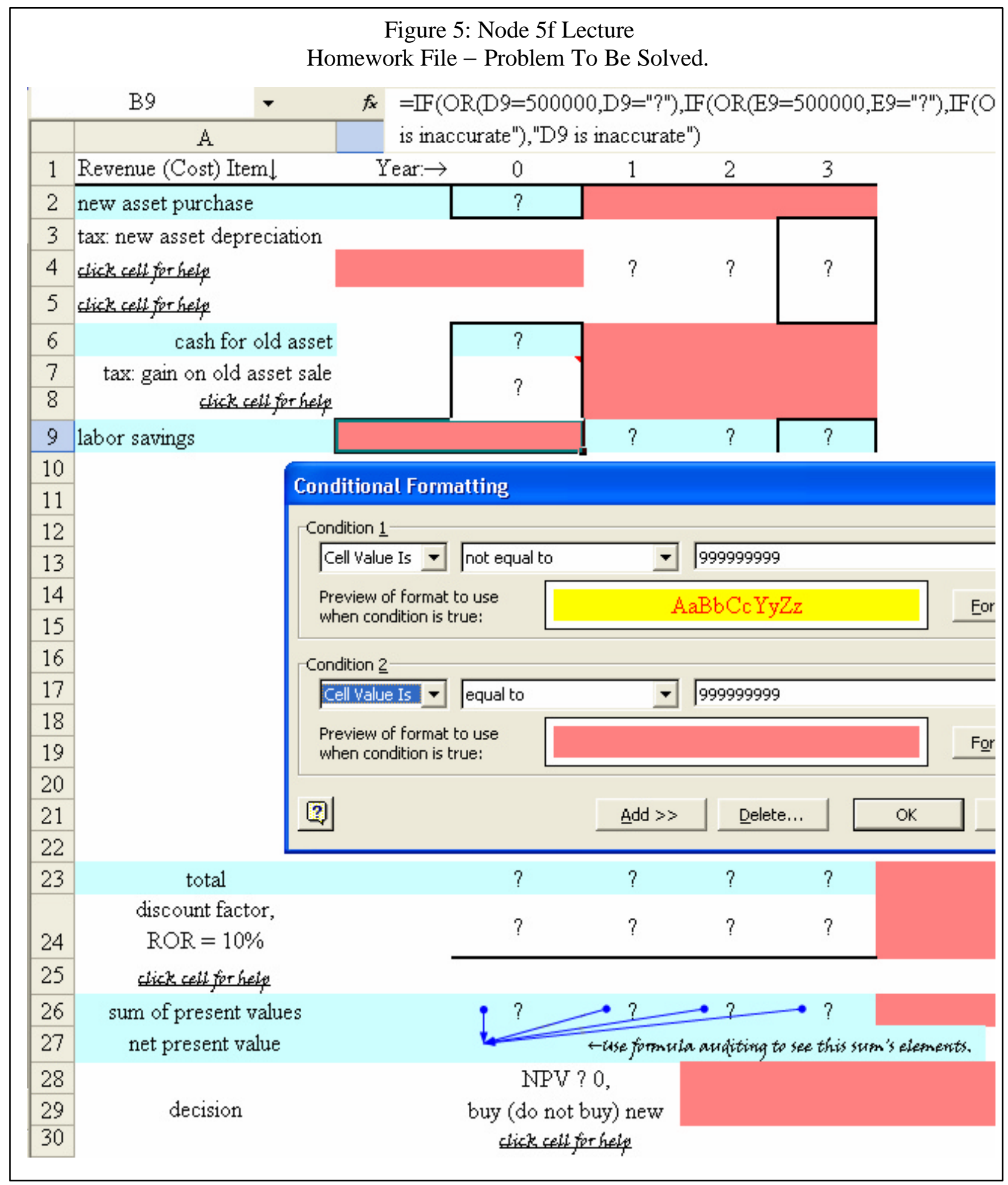


The interactive "helps" in this example (Figure 4) are as follows.

1. Cells A5, A8, A11, A15, and A18 link to the same PowerPoint presentation about tax shields. This concept can initially be difficult, and the PowerPoint presentation slowly walks through and illu strates the concept - one slide and issue at a time. More capable students may rely on the lecture of this PowerPoint presentation, but less capable students can replay this part of the lecture until they understand it and can perform the analysis. Cell A21 also links to a PowerPoint presentation. However, it is more extensive - paralleling the content usually placed in a hard-copy technical appendix about a computational method. The files are ppt files that open in PowerPoint.

2. A4, A13, and C/D26 link to html page s that contain explanations about computation methods, concepts, and decision rules. These explanations are shorter and less complex than what is found in the PowerPoint presentations. The html files open quickly in the browser.

3. Each "click cell for help" link has a pop-up "screen tip" activated by a mouse cursor rollover. One of these rectangle pop-ups is shown over cells A/B9. They explain the nature and media for the help, and of course, quickly appear and disappear with the movement of the mouse's cursor.

4. Four rectangular comments are shows in columns G/H/I. These comments give the detailed computation underlying a number in the cell, and they briefly state a key issue that determines how the computation is structured. As with screen tips, they are activated by a mouse rollover on the indicated cell (where a small red triangle appears in the top right corner of the cell).

Figure 5 shows portions of the node $5 \mathrm{f}$ file students initially encounter when they link to homework 1449 from the segment file. (To access the Figure 4 solution file, students add a designated character to the Figure 5 file's URL. When opened, all of the files - WORD (doc or html), EXCEL (xls or html), and PowerPoint (ppt or html) - display URLs since they are opened from the browser. For example, if the Figure 5 file's URL is http://...homework-14-49.xls, students add a dollar character http://...homework14-49.xls to access the solution file for the homework.

Students work with the Figure 5 file, entering data to solve the problem. The problem and file have to be sufficiently structured so students enter data in the correct place and in the correct form. The pop-up "helps" in Figure 5 are based on exact cell-data locations and form (e.g., a number rounded to three decimal places in cell D20. Without this precision, if functions and conditional formats will not work.

Figure 5 illustrates the display of error messages (or "helps") with the combined use of if functions and conditional formats. Cell B9 has coral colored fill and no text. However, if an inaccurate number is entered in D9, E9, or F9, an error message appears in B9 with yellow fill and red text. The message identifies the cell with the incorrect number, or with more space available, it could provide brief hints or "helps.". When the number is corrected, the message disappears and B9 returns to a solid coral color. In Figure 5, the if function formula for cell B9 is shown in the formula bar. The conditional formatting dialogue box is directly below row 9 . (Technically, the number 999999999 generated by the if function is used to activate the conditional format.)

Figure 5 also illustrates the use of formula auditing. When cells are mathematically combined (cells C26, D26, E26, and F26 are added), their connection to the computation's result (cell C27) can be displayed by a set of arrows drawn between the cells. This display is activated (or removed by menu items on the formula auditing toolbar. This feature of EXCEL helps students see the connection between and sequence of $(\bullet)$ one computation or $(\bullet)$ a chain of computations.

\section{Summary File}

The summary file is not used to give lectures, but exists for the instructor and students' conve nience. It is a WORD ge nerated html file, and contains the cut-and-paste sum of the lecture files (anchor, segment, and segment element files). Thus, the summary file does not contain links to topic materials or interac- 


\section{Self-Study Interactive Lectures}

tive features found in lecture files. They lose their interactivity because of the way they are pasted into a summary file. Primarily to reduce file size, interactive fe atures are dropped when files such as EXCEL problem-solving files are pasted into a summary file. Also, because of difficulties in transferring EXCEL lecture-file page widths into a WORD summary- file so that the summary-file page widths are retained, the print screen function is often used to copy a file and paste its image into a summary file.

There are at least four uses of summary files.

1. They contain the full set of lecture material for a topic, and can be used by the instructor as a concise reference to prepare for class.

2. Students can use them as a reference during the in-class lecture. Some classrooms can present cha 1lenges in seeing all detail on a computer projection screen - making a hardcopy on the student's desk useful. Also, corrections (edits) to a lecture file can be made verbally as the lecture is given, and students need to be able to make a hardcopy edit.

3. Printing out a single summary file is much quicker and shorter in page length than printing out a set of separate lecture files. This can be particularly important to students using at-work or campus lab facilities.

4. Often students encounter difficulties in downloading or FTPing a set of lecture files ( see the technical difficulties section below for more on these problems). Complete lecture coverage of a topic is quickly downloaded off the web as a single, limited-size summary file. This works well even if a student has a slow dial- up connection. Also, students can experience delays in learning about FTPing lecture files, alternative software and media for copying files to CDs, and accessing servers through alternative campus computer labs (see the technical difficulties section below for more on these problems). Getting a summary file off the web provides access through almost any computer at any location by any student. This translates to fast start-up and easy access - no delay for learning technology or getting access to files.

\section{Future Design Features}

Characteristics of SSIL not used in this version include interactive dialogues and outline files. The following discussion presents the possible uses of these characteristics and some of the design features a ssociated with their use.

In the specific course involved, the author who prepared this example does not lec ture conceptual material using instructor-student discussions initiated by the instructor. Discussion is limited to answering questions asked by students. However, discussions of concepts could be structured as interactive dialogues. One possible design is that an issue is posed, with students asked to comment on defined aspects of the issue. As ideas are put forward, mouse rollovers or some other programmed scheme could reveal the idea as previously developed by the instructor and perhaps ask questions as extensions of the idea. Or, the instructor could type in, as the idea is put forward, a much abbreviated "thumbnail" of the idea. The instructor intends to try this type of interactive dialogue in an electronic classroom in the Spring of 2003. The updated file will be uploaded from the instructor's workstation to the classroom server, and each student can download it immediately to his/her desk computer.

Another interactive dialogue possibility is to pose multiple choice questions to test students' absorption of the lecture material as sections of the lecture are being given or completed. This should involve a link off the lecture-notes page to hide the source material. Depending on students' answers, the instructor can navigate back to the source page to clarify and improve students' comprehension or go on to the next unit of topic material. 
Another file to be designed as part of the full set of SSIL files is an outline file. This file will be an outline and site map of all the other files. The outline descriptions are the minimum necessary to identify a lecture file, with each part of the outline containing a link to the file. This page's purpose is to enable students to readily group lecture components they are interested in, and save or print them. For example, some students may want to print out problem-solution files for stud ying a quantitative method. Using the outline file is more efficient than navigating through the lecture file sequence (anchor, to major segment, to segment element) to get to a file to save/print. Linking from the outline file may also be less subject to corruption than cutting and pasting components off the summary file to one or more pages for print out.

\section{The Power of SSIL: Better Topic Coverage and Empowered Self-Study}

Obviously, the scope of coverage increases when the interactive tutorials move from single topic coverage to coverage of all course lectures. At a minimum, this gives students an essentially complete set of lecture notes in the form of OFFICE files, which can be helpful to students in writing down lecture notes or when the information is to be communicated in a web course. So far, this is unremarkable pedagogy.

For a number of years, some profound cultural forces have been at work in accounting education where we teach, and in accounting education throughout much of the United States. Albrecht and Sack state (Albrecht, 2000): "The number and quality of students electing to major in accounting is decreasing rapidly." A local newspaper article a few years ago said fifty percent of our University's incoming freshmen could not read at a college level, implying this problem in accounting education at our university. Additionally, many accounting programs, including ours, have experienced changing demographics for students, such as an increase in students who have English as a second language. Two ways to address these problems and meet students' needs are to lecture more slowly or to write what is to be learned on the chalkboard. These teaching approaches make keeping pace with and understanding lectures easier, but limit the breadth of material to which a student will be exposed because time limits the amount of material that can be slowly stated or written on the chalkboard. Some describe this solution as reaching the "lowest common denominator."

A more profound impact of the changing educational environment - than the breadth of topic material covered - is on the level of complex analysis that can be reached in classroom lectures. How does an instructor deal with student learning challenges without simplifying the topic material to a level easily understood by students with learning, reading, or comprehension difficulties. We view SSIL as a tool that will ameliorate the learning difficulties that arise from these varied stude nts. Specifically, we believe SSIL provides the following learning mechanisms and benefits:

1. The complete lecture files give students with limited English-language skills the ability to reexperience and study lectures in the exact presentation sequence and with the same content as orig inally heard. This self-study can be done at an individual's own reading-comprehension pace and with the aid of dictionaries if needed. The premise for this benefit is that the instructor uses the same files to present the lecture.

2. The opportunity to self- study a lecture at one's own comprehension speed is also a benefit to students with limited skills in reading, analysis, and listening comprehension or with limited business or accounting aptitudes. Moreover, an instructor can provide a complete range of topic material in the lecture files that are integrated into the lecture, i.e., touched on but not thoroughly discussed in class. In effect, it is context sensitive help where a student can view and study remedial or more thoroughly explanatory material if needed. The OFFICE mechanisms for provid ing the support materials are pop-up comments, links to support files, or PowerPoint presentations to which a student can link. 


\section{Self-Study Interactive Lectures}

3. The above features of SSIL also provide further study bene fits to students with deficiencies in educational backgrounds, including lack of prior exposure to topics in the core or prerequisite courses. These students may also need to study a series of topics on a remedial level.

What is particularly attractive about self-study interactive lectures is they provide instructors with a way to retain lecture thought-complexity while not losing less capable students or being overwhelmed by the time available for class lectures. SSIL help enable complex thought development in lectures in three ways. (1) A large amount of class time is freed by not having to use the chalkboard except for points of emphasis. This creates time for a fuller development of more complex ideas. (2) Students can print out and pre-study the lectures, reducing pressure on an instructor to teach in strict conformance with other source materials that students can study before a lecture - i.e., pressure to "teach the book." (3) Students know that they can recreate lecture thought development - in fact the entire lecture - at home, even if a student gets somewhat lost or confused in class. This should reduce student anxiety levels and pressures toward reduced breadth and depth of topic coverage.

A primary reason to use this type of lecture and self-study tool is that the topic coverage can be increased in terms of information content and academic rigor. SSIL have a close connection to what is happening in class because they are used by the instructor to lecture. They engage the student and instructor in an identical information base for study, where the instructor uses the discussion material and interactive problem-solving features in class, and students study a complete set of files containing the same material.

\section{Impressions from Class Testing}

The motivation for developing SSIL was to enhance the learning experience of the students. Therefore, importance rests on what parts of SSIL students actually use and perceive to be important. Accordingly, we surveyed students to determine their use of the SSIL tools. Faculty who were not using SSIL administered the surveys without the instructor present and compiled the results. Two classes were surveyed at mid-term and again at the end of the term. Each student selected a code to identify their follow-up response. Sixty seven students responded to the first survey and sixty five students responded to the second survey.

Students were asked to score each tool: Textbook, Anchor File, Homework Links, and the Summary File. The scale used by the students was: 1 - Frequently, 2 - Occasionally, 3 - Seldom, 4 - Never. On the mid-term surveys students were also asked about several potential demographic differences: Gender, English as a second language, Overall grade point average (GPA), and Accounting GPA. A nonstatistical analysis of these results follows.

Table 1 reports the average scores by gender for each tool. Female students used the textbook more than males but they used the Summary file with the same frequency. On balance, we conclude that the stur dents' report on the use of the tools is unrelated to gender.

\begin{tabular}{|l|c|c|c|c|c|}
\hline \multicolumn{7}{|c|}{ Table 1: Use Related to Gender } \\
\hline & TEXTBOOK & ANCHOR & HOMEWORK & SUMMARY & AVERAGE \\
\hline Female & 2.06 & 2.20 & 2.11 & 1.40 & 1.94 \\
\hline Male & 2.40 & 2.05 & 1.90 & 1.40 & 1.94 \\
\hline AVERAGE & 2.23 & 2.12 & 2.00 & 1.40 & 1.94 \\
\hline
\end{tabular}

Table 2 reports the average scores by whether English is the student's second language. As anticipated, students for whom English is a second language use the anchor file more frequently than the other stu- 
dents. They also used the summary file frequently although not more frequently than the other students. On average there is no difference between the two groups.

\begin{tabular}{|l|c|cc|c|c|}
\hline \multicolumn{7}{|c|}{ Table 2: Use Related to English as Second Language } \\
\hline & TEXTBOOK & ANCHOR & HOMEWORK & SUMMARY & AVERAGE \\
\hline $\begin{array}{l}\text { English is primary } \\
\text { language }\end{array}$ & 2.10 & 2.31 & 2.08 & 1.33 & 1.96 \\
\hline $\begin{array}{l}\text { English is second } \\
\text { language }\end{array}$ & 2.25 & 1.86 & 2.00 & 1.50 & 1.90 \\
\hline AVERAGE & 2.18 & 2.08 & 2.04 & 1.42 & 1.93 \\
\hline
\end{tabular}

Table 3 reports the average scores by overall GPA. The use of SSIL is in the same order as the students' GPAs. There was one anomaly with each tool but we conclude that students with lower GPAs make more use of SSIL. This result is probably because students with lower GPAs have greater difficulty understanding the technical material of a textbook. This is the desired outcome for SSIL because it was developed in large part to assist students with learning difficulties.

\begin{tabular}{|l|c|c|c|c|c|}
\hline \multicolumn{7}{|c|}{ Table 3: Relationship of Use to Overall GPA } \\
\hline GPA & TEXTBOOK & ANCHOR & HOMEWORK & SUMMARY & AVERAGE \\
\hline Over 3.5 & 2.20 & 2.50 & 2.13 & 1.47 & 2.08 \\
\hline $3.0-3.5$ & 2.12 & 2.19 & 2.19 & 1.38 & 1.97 \\
\hline $2.5-3.0$ & 2.27 & 1.91 & 1.91 & 1.27 & 1.84 \\
$2.0-2.5$ & 1.75 & 2.00 & 1.50 & 2.00 & 1.81 \\
\hline AVERAGE & 2.08 & 2.15 & 2.08 & 1.53 & \\
\hline
\end{tabular}

Table 4 reports the average scores by Accounting GPA. The results were consistent with the scores based on overall GPA; however, they indicate slightly higher usage. The difference is not significant except for the Summary File, which does indicate significantly higher usage. The scores should be the same between the ove rall GPAs and Accounting GPAs except for the fact that a simple average was used rather than a weighted average. Any significant difference should be between the distribution within the GPAs, i.e., higher GPAs may have a higher score and lower GPAs a lower score, or vice versa. We expected that the greater use of the tools would be related to Accounting GPA more than to overall GPA and the results support this expectation.

\begin{tabular}{|l|ll|c|c|c|}
\hline \multicolumn{7}{|c|}{ Table 4: Relationship of Use to Accounting GPA } \\
\hline $\begin{array}{l}\text { ACCOUNTING } \\
\text { GPA }\end{array}$ & TEXTBOOK & ANCHOR & HOMEWORK & SUMMARY & AVERAGE \\
\hline Over 3.5 & 2.28 & 2.56 & 2.06 & 1.17 & 2.01 \\
\hline $3.0-3.5$ & 2.27 & 1.95 & 2.14 & 1.36 & 1.93 \\
\hline $2.5-3.0$ & 2.17 & 2.25 & 1.83 & 1.50 & 1.94 \\
\hline $2.0-2.5$ & 1.63 & 1.75 & 1.88 & 1.13 & 1.59 \\
\hline AVERAGE & 2.06 & 2.13 & 1.98 & 1.29 & \\
\hline
\end{tabular}




\section{Self-Study Interactive Lectures}

Demographics in general did not seem to make any differences except for the Summary tool. The survey at the end of the course did not include any demographic information. The purpose of the follow-up survey was to determine whether use changed during the term. Identifiable individual surveys were compared. There was no systematic change between the mid-term and follow-up surveys. However, there were few instances of score changes of more than one, i.e., a student who scored a particular item on the mid-term survey as a two, generally scored the same item as a two on the follow-up survey but rarely scored a number of four. Table 5 reports the average scores on each tool for the mid-term and for the follow-up surveys.

\begin{tabular}{|l|c|c|c|c|c|}
\hline \multicolumn{7}{|c|}{ Table 5: Comparison of Mid-Term and Follow-Up Surveys } \\
\hline \multicolumn{1}{|c|}{ SURVEY } & TEXTBOOK & ANCHOR & HOMEWORK & SUMMARY & AVERAGE \\
\hline FOLLOW-UP & 2.57 & 2.26 & 2.14 & 1.54 & 2.13 \\
\hline MID-TERM & 2.18 & 2.08 & 2.04 & 1.42 & 1.93 \\
\hline
\end{tabular}

Each tool was used less at the end of the semester than at mid-term. There were only a few diffe rences in the individuals who responded to the survey, so it is clear that students, as a group, used the tools less by the end of the term. Future surveys should include information on the cause of this decline in use, if there is a decline. Currently, one can only speculate as to the cause of this decline in use.

\section{Conclusions}

Self-study, interactive lectures (SSIL) address what appears to be a pervasive problem that has emerged in accounting education - at least at our university. The power of this methodology is discussed extensively in the third major section of the paper. A central issue is: how do you keep lectures high in information content and more rigorous in discussion and problem complexity when a significant percentage of the class cannot keep up with this level of instruction? We suggest web-based "multi-media" lectures for an entire semester course, allowing students to concentrate on lecture content while in class without having to take extensive notes. These "lecture notes" allow students to repeatedly go through a lecture at home as if it were on video; but interactively work through the lecture and quantitative problems on the computer.

This paper describes self-study interactive lectures (SSIL) that are computer-based, interactive lecture notes used by the instructor during class lectures. SSIL is not proposed as lowest common denominator instruction, far from it. SSIL supports home reproduction and study of lectures, and thus enables a far greater depth of instruction than might otherwise be possible with students who may have learning difficulties.

\section{References}

Brecht, H.D., Sauls, E., \& Beirne, T.J. (2000). Context Enriched Spreadsheets: A Tool For Addressing Pedagogical Dilemmas Posed by Bi-Polar Student Characteristics. WSDI 2000 - Maui Proceedings.

Albrecht, W.S. \& Sack, R.J. (2000). Accounting Education: Charting the Course through a Perilous Future. American Accounting Association. Accounting Education Series, Volume No. 16, page 1. 